\title{
Results of W-87/Mk21 Deployment Separation Shock Tests
}

\author{
C.A. Avalle
}

April 21, 1999

Lawrence

Livermore

National

Laboratory 


\title{
Results of W-87/Mk21 Deployment Separation Shock Tests
}

\author{
Test Performed at the \\ Survivability and Vulnerability Integration Center \\ Hill AFB
}

October, 1998

Carlos A. Avalle
Defense Sciences Engineering Division
Lawrence Livermore National Laboratory

April 21, 1999 
This report summarizes results of the W-87/Mk21 Deployment Separation Shock Tests conducted at the Survivability and Vulnerability Integration Center (SVIC) at Hill Air Force Base in Ogden, Utah, from 10/5/98 to 10/8/98. Specific details regarding the test plan and procedures can be found in the Master Test Plan listed in the references.

\section{Test Objectives:}

- Evaluate the performance of a set of servo accelerometers during and post Re-entry Vehicle (RV) separation events. These ultra-sensitive accelerometers ( $\mu \mathrm{g})$ needed to operate during and after the separation shock events and these tests would serve as confirmation of proper functioning. These sensors were later flown on FTU-15, a development flight unit supporting the Instrumented High Fidelity Joint Test Assembly Program, as part of an experimental Inertial Measurement Unit (IMU) to measure RV dynamics during RV mechanical separation and spin-up.

- Measure separation shock response at the IMU accelerometer locations.

- Measure separation shock response at locations on the warhead and RV common to locations used on MMIII separation tests conducted at LMMS Valley Forge for data comparison.

Test Team:

Test Director: Kim Owen (LMET)

Test Engineer: Saeed Emadi (LMR)

Test Design Engineer: Dick Johnson (TRW)

Test Integration Engineers: Terry Lindman (LLNL); John Leibenberg (SNL) POC and Test Conductors: Jerry Harper (SVIC / Boeing), Del R. Wilson (SVIC) Test Setup Engineer: Mark Goodrich (Lockheed Martin)

SVIC Instrumentation: Dixon Walker (SVIC / Boeing)

DOE Instrumentation: Carlos Avalle (LLNL)

Quality Assurance Engineer: Jim Fisher (Boeing)

Safety Officers: Dave Carnahan (LMES); K.C. Jones (SVIC / Boeing)

Experimenters / Test Directive: Carlos Avalle (LLNL); John Leibenberg (SNL); Jerry Harper (Boeing)

Test Description:

The tests were conducted in Building 501 of the Hill Air Force Base Survivability and Vulnerability Integration Center (SVIC). DoD provided a Peacekeeper deployment module (DM) and a counterbalance system for the RV. DoD defined a worst case shock DM configuration and RV positions on the DM. Other mock RVs were placed on the DM (Fig. 2) in order to simulate mass loading on the DM at the time of FTU-15 separation (as predicted for the upcoming GT-28 Peacekeeper test flight). DOE (LLNL/SNL) provided the instrumented test unit, FTQU-15. DoD provided the remaining hardware, DM tie-down kits, ordnance, and data acquisition system (DAS). DOE provided the shipping to/from Hill AFB.

Table 1 provides some details on the types of sensors on-board the test unit (FTQU15), their locations, orientations, ranges, and sensitivities. Figure 1 shows the location of these sensors within the RV. A more comprehensive description of the sensors, their intended application, and data acquisition interface are provided in the appendix. 
In addition to the sensors on-board the test unit (FTQU-15), DoD provided a response accelerometer on the DM in the vicinity of the tiedowns for the test unit (Fig. 2), and a Scanning Laser Vibrometer system to collect RV displacement and velocity information after RV separation and lift-off.

The test was executed as outlined in the Master Test Plan with very few alterations, and these were mainly in the configuration of the DAS. A procedural flowchart of the test sequence is shown in figure 3. A total of four separation events (rather than three as originally planned) were performed. Data was recorded on all channels, in all events, with at least two successful runs per channel. The first test run experienced difficulties with the pneumatic system which failed to lift the RV off the DM platform after firing tiedown ordnance. The test was not entirely a null since useful sensor baseline response data was collected without RV displacement. In run 2, the pneumatic problem was corrected but the RV lift-off velocity was higher than desired. In addition, one channel (A8T) had some noise coupling in the signal leads. These problems were corrected and other minor adjustments made for the next two runs. Runs 3 and 4 were completed successfully, with run 3 best overall. The data plots from this run and a discussion of the analysis are attached to the appendix.

Data Analysis and Test Results:

SVIC instrumentation technician provided experimenters raw data time-history printouts of all test channels for review after each run. A minimum amount of data analysis was performed in real-time, basically, a review of these printouts by the test experimenters in order to refine test parameters or to select signal segments for archival storage. Review of these printouts was sufficient to satisfy the immediate goals of the test, namely, to determine the survivability of the servo accelerometers and verify that no saturation occurred during the shock event. Servo accelerometer data fell within predicted limits and all of these sensors performed flawlessly during and after the separation shock, as designed. Analysis of the accelerometer data to extract displacement and velocity information for comparison with the laser vibrometer data has not been completed. Response accelerometer data appears to be similar in character to that of previous separation tests. A thorough analysis and comparison, including Shock Response Spectra (SRS) plots, also remains to be completed. All of the test objectives were met and the test was deemed a success. 


\section{INSTRUMENTATION SCHEDULE for W87/Mk21 RV Separation Test - Little Mountain Test Facility}

\begin{tabular}{|c|c|c|c|c|c|c|c|}
\hline $\begin{array}{l}\text { Sensor } \\
\text { ID }\end{array}$ & Description & $\begin{array}{c}f \text { Range } \\
(\mathrm{Hz})\end{array}$ & $\begin{array}{c}\text { Sensitivity } \\
\text { (Volts/g) }\end{array}$ & $\begin{array}{c}\text { F. S. Range } \\
\text { (g's) }\end{array}$ & $\begin{array}{l}\text { Sensor } \\
\text { Model }\end{array}$ & Location & Orientation \\
\hline$A 1 C$ & NEP1 ug & $D C-100$ & 10 & \pm 0.5 & QA-3100 & NEP aft & Circumferential $\left(250^{\circ}\right)$ \\
\hline $\mathrm{A} 2 \mathrm{C}$ & NEP1 response & DC-10K & 0.01 & \pm 50.0 & PCB J353B17 & On NEP1 mount & Circumferential $\left(250^{\circ}\right)$ \\
\hline A3R & NEP2 ug & $D C-100$ & 10 & \pm 0.5 & QA-3100 & NEP aft & Radial $\left(10^{\circ}\right)$ \\
\hline A4R & NEP2 response & DC-10K & 0.01 & \pm 50.0 & PCB J353B17 & On NEP2 mount & Radial $\left(10^{\circ}\right)$ \\
\hline A5R & NEP3 ug & $D C-100$ & 10 & \pm 0.5 & QA-3100 & NEP aft & Radial $\left(130^{\circ}\right)$ \\
\hline A6R & NEP3 response & DC-10K & 0.01 & \pm 50.0 & PCB J353B17 & On NEP3 mount & Radial $\left(130^{\circ}\right)$ \\
\hline$A 7 X$ & AFT support response & DC-10K & 0.01 & \pm 300 & PCB J353B17 & On AFT support & $X\left(90^{\circ}\right)$ \\
\hline A8T & AFT bulkhead ug & $D C-100$ & 1.923 & \pm 1.3 & QA-2000 & AFT bulkhead & Tangential \\
\hline A9X & $\begin{array}{l}\text { AFT bulkhead } \\
\text { response }\end{array}$ & $D C-10 K$ & $7.00 E-04$ & \pm 300 & Endevco $7270-2 \mathrm{~K}$ & AFT bulkhead & X (On axis) \\
\hline 10 A10X & WES deck response & DC-10K & $7.00 E-04$ & \pm 300 & Endevco $7270-2 \mathrm{~K}$ & WES deck & $X\left(288^{\circ}\right)$ \\
\hline 11 A11X & WES deck response & $D C-10 K$ & $7.00 E-04$ & \pm 300 & Endevco $7270-2 \mathrm{~K}$ & WES deck & $X\left(294^{\circ}\right)$ \\
\hline 12 A12 & A3R Raw & DC-10K & 10 & \pm 10 Volts & Analog channel & NEP aft (A3R) & $A 3 R$ \\
\hline
\end{tabular}

Table 1, Instrumentation Schedule 


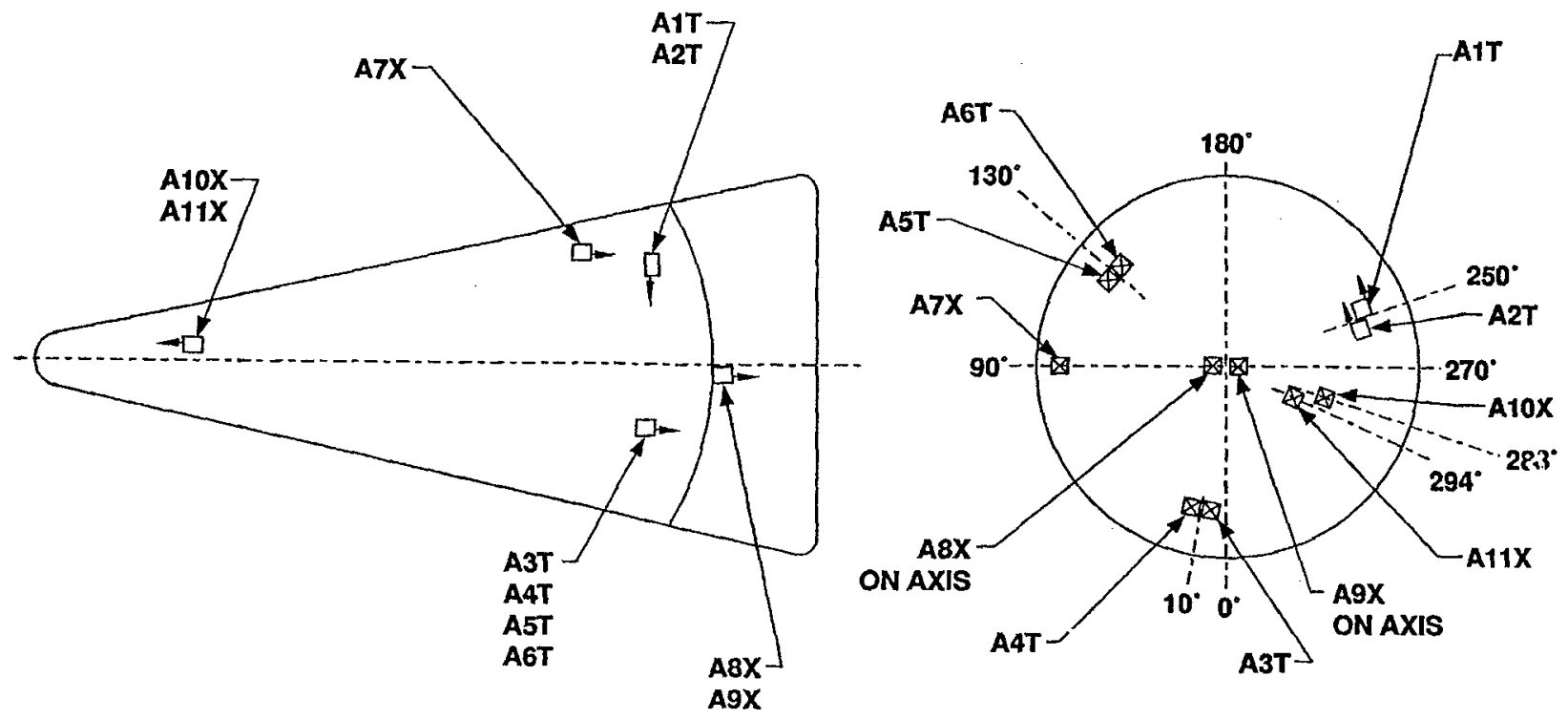

Fig. 1: FTQU-15 Test Unit Accelerometer Locations

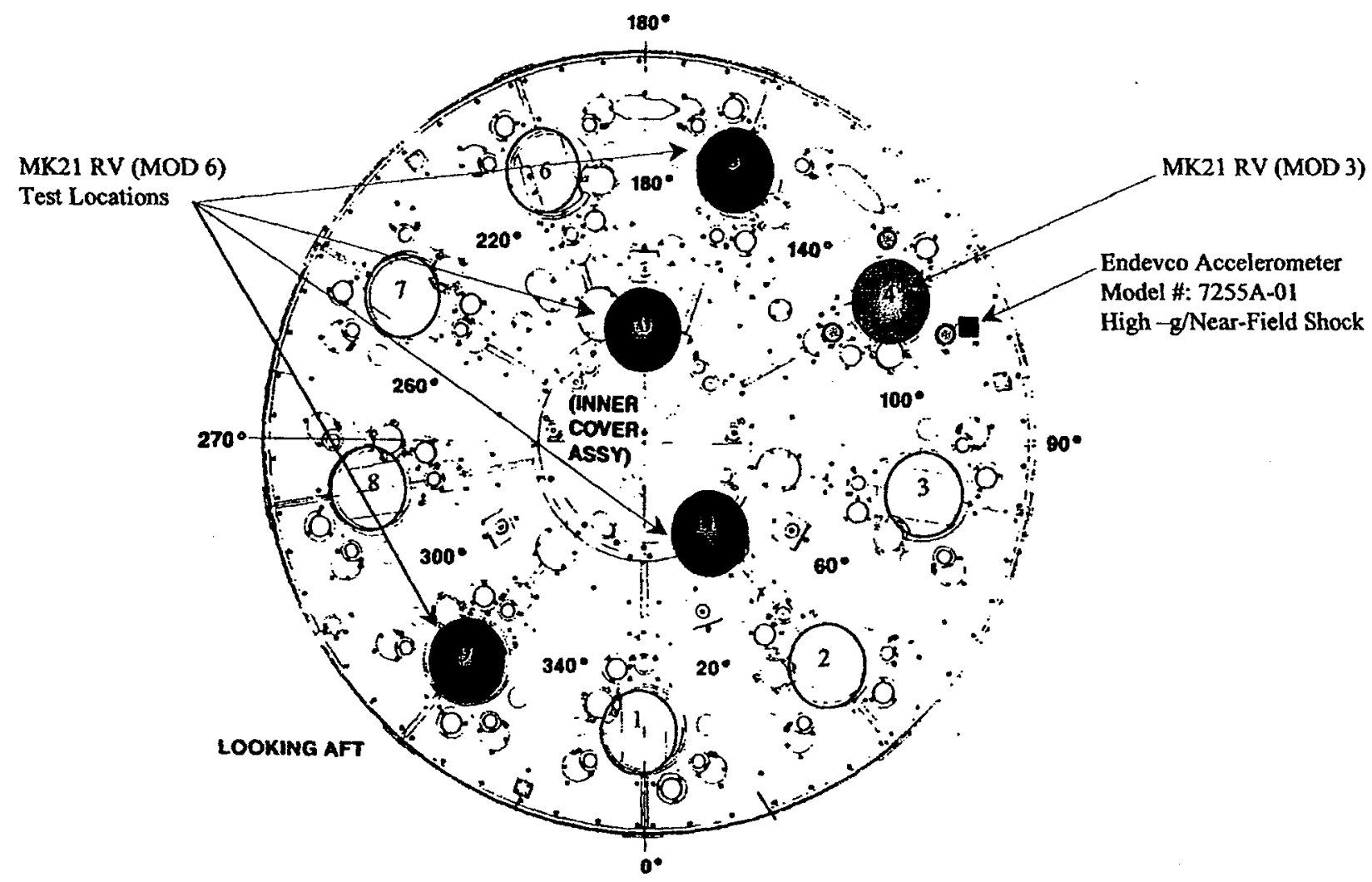

Fig. 2: RV Positions on Peacekeeper Deployment Module and Bulkhead Measurement Location (Looking Aft) 


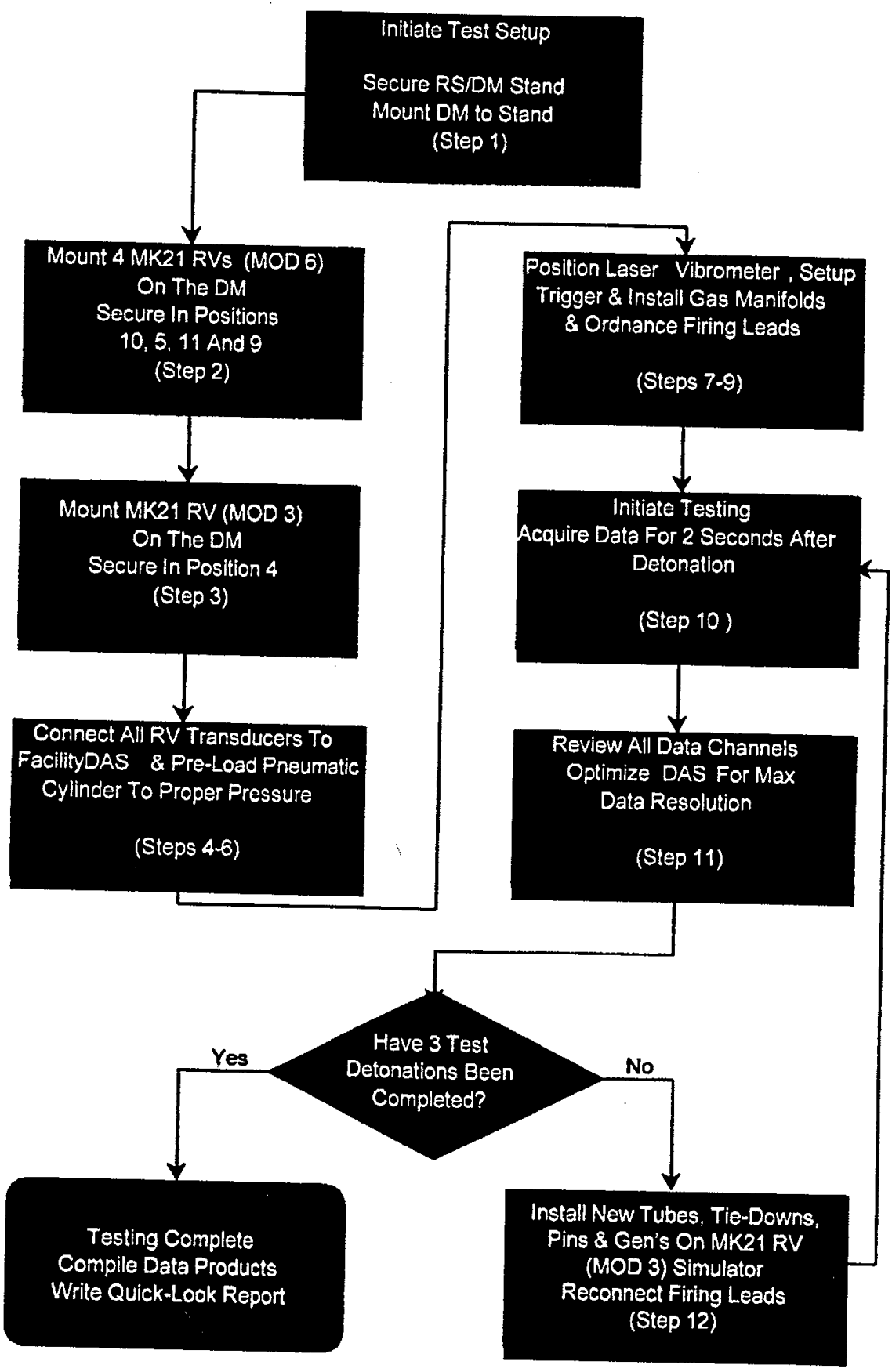

Fig 3: Procedural flow chart of the test sequence 


\section{References}

LMET/BOEING S\&V Engineering Test Log, document 99SV041; Jerry Harper, SVIC / Boeing, October 1998

MK21 Deployment Separation Shock Test (Test Plan PRIME-00648); Richard V.

Johnson, TRW ICBM Operational Systems, September 1998

RV Separation Test - DOE Requirements, memorandum from Dick Baxter (LLNL) to Jim Oldham (USAF ICBM Systems Project Office); July 1998

Data Report, JTU-2 Flight Separation Shock Tests, Enclosures I -V; W. L. Whitney, TRW Systems Integration Group, August 1986 


\section{Appendix A}

Instrumentation List Details

The following is a description of the sensors on-board the test unit, instrumentation, and their intended application. Please refer to table 1, Instrumentation Schedule for RV Separation Test (pg. 4).

'NEP $\mu$ g' accelerometers (A1C, A3R, A5R): These are servo accelerometers (model QA3100) mounted on the aft section of the Nuclear Explosives Package (NEP). We were interested in characterizing these sensors for survivability and response during the separation shock. These are low frequency sensors and their output does not represent the shock level at their locations but rather measure the RV displacement and its derivatives during the separation movement. Two of these sensors (A3R, A5R) were oriented in a longitudinal direction, with their sensitive axis along the RV's axis of symmetry. The third sensor (A1C) was oriented in a circumferential direction, transverse to the symmetry axis.

'NEP response' accelerometers (A2C, A4R, A6R): Response accelerometers (model PCB $\mathrm{J} 353 \mathrm{~B} 17$ ) were installed on each of the QA-3100 mounts to characterize the excitation shock at each mount location. These sensors are higher frequency types $\left(f_{c}>10 \mathrm{KHz}\right)$ with fast response to measure the actual shock input to the QA-3100 accelerometers.

'AFT support response' accelerometer (A7X): Response accelerometer (model PCB J353B17) was mounted on the aft support in an axial direction to characterize the shock at that location. This location is common to past separation tests and is intended for use in correlating data to past RV separation tests.

'AFT bulkhead $\mu \mathrm{g}$ ' accelerometer (A8T): This is a servo accelerometer (model QA-2000) mounted on the aft bulkhead. This sensor is being characterized for survivability and recovery after the separation shock.This sensor in intended for RV dynamics measurements during and after RV separation.

'AFT bulkhead response' accelerometer (A9X): Response accelerometer (model Endevco $7270-2 K)$ to characterize the shock input at the QA-2000 mount.

'WES deck response' accelerometers (A10X, A11X): Response accelerometers (model Endevco 7270-2K) mounted on the WES deck to characterize the shock at those locations. These sensors and locations are also common with past RV separation tests and will aid in correlating data to these tests.

'Check channel' (A12): This spare DAS channel monitored the raw output signal from the A3R NEP $\mu$ accelerometer, bypassing all but the dynamic ranging components in the builtin signal conditioning and filter module.

\section{Additional Sensors / Instrumnetation}

An additional Deployment Module (DM) accelerometer (Fig. 2, pg. 6) was provided by SVIC and mounted on the Mk-21 DM near the RV tiedowns to characterize the input shock to the RV at the tiedowns. A Scanning Laser Vibrometer (Photo 6, pg. 13) was also provided by SVIC to externally measure RV displacement during separation. 


\begin{abstract}
All test unit (FTQU-15) sensors were procured, calibrated, and installed by the DOE Organizations (LLNL and SNL) prior to shipment of the test unit to the test site. Signal conditioning hardware provided the proper excitation, filtering, and amplification for the sensors to interface to the Data Acquisition System (DAS). Sensors A1C through A7X were interfaced to the (DAS) through stand-alone, or built-in (e.g., QA-3100's) signal conditioning provided by DOE. All other sensors were interfaced to the DAS via a signal conditioning rack located in the vicinity of the DM frame provided by SVIC.
\end{abstract}

\title{
Data acquisition
}

Signals were acquired by the SVIC DAS and stored on digital tape. All channels were recorded over a 3 second time interval in addition to a $100 \mathrm{msec}$ pre-trigger leader. The data was reduced and archived in digital format at the SVIC, transferred onto CD and shipped to the DOE organizations for further processing and analysis. 


\section{Appendix B}

Data Printouts, Descriptions, and Interpretation

The following is a description of the channel-by-channel printouts (attached) of the data from Run 3 of the RV Separation test, and interpretation of the plots. Only data from this run is presented because it typifies results obtained in the other runs and represents the best of the set. Please refer to Appendix A for a description of sensors and applications as well as the Instrumentation Schedule table.

Page B-3, Deployment Module accelerometer: This is the shock response at a location on the DM in the vicinity of the RV tiedowns. Shock levels range from about -820 to $+928 \mathrm{~g}$ peak. Shock event duration is approximately $50 \mathrm{msec}$ with a time constant of about 10 msec.

Page B-4, A1C NEP $\mu$ g accelerometer: Response of the circumferential servo accelerometer to input shock and RV lift-off. Positive acceleration swing during initial $10 \mathrm{msec}$ response to the ordnance shock event, followed by a $100 \mathrm{msec}$ response to RV lift-off. Oscillatory response to the end of the record represents lateral accelerations due to pendular swaying of the RV after lift-off. This accelerometer was oriented transverse to the lift-off vector. Peak accelerations are a factor of 10 smaller than that of the axial accelerometers (A3R, A5R).

Page B-5, A2C accelerometer: Shock response at the A1C $\mu$ g accelerometer mount. Initial shock peak levels from -55 to $+50 \mathrm{~g}, 20 \mathrm{msec}$ duration, followed by smaller amplitude reflection and ringing for another $80 \mathrm{msec}$. This response characteristic is very typical of data seen in past RV separation tests.

Page B-6, A3R NEP $\mu$ g accelerometer: : Response of axial servo accelerometer to input shock and RV lift-off. Positive acceleration over initial $350 \mathrm{msec}$ followed by deceleration and bouncing as the RV is lifted off the DM platform, reaches its maximum travel extension, comes to a stop, and bounces for the remainder of the data record. No evidence of damage, or saturation due to input shock. A low-pass-filter $\left(f_{c}=8 \mathrm{~Hz}\right)$ in the sensor's signal conditioning module filters out the high-frequency shock components and respond only to the low-frequency displacement accelerations during and after lift-off.

Page B-7, A4R accelerometer: Shock response at the A3R $\mu \mathrm{g}$ accelerometer mount. Response characteristics appear very similar to that of A2C accelerometer (see pg. B-3 description).

Page B-8, A5R NEP $\mu$ g accelerometer: : Response of axial servo accelerometer to input shock and RV lift-off. Response characteristics appear very similar to that of A3R $\mu \mathrm{g}$ accelerometer as expected since these are identical sensors with the same orientation (see pg. B-4 description).

Page B-9, A6R accelerometer: Shock response at the A5R $\mu \mathrm{g}$ accelerometer mount. Response characteristics appear very similar to that of A2C accelerometer (see pg. B-3 description).

Page B-10, A7X AFT support accelerometer: Shock response at the AFT support location. Response characteristics appear very similar to that of the NEP response accelerometers, except peak amplitudes are slightly higher as would be expected (see pg. B-3 description). 
Page B-11, A8T AFT bulkhead $\mu$ g accelerometer: : Response of bulkhead servo accelerometer to input shock and RV lift-off. This accelerometer was mounted in a transverse direction and therefore the response of the accelerometer is closer in nature to that of the circumferential NEP $\mu \mathrm{g}$ accelerometer (A1C) than to that of the radial sensors (A3R, A5R). The accelerometer is responding to lateral motion of the RV after lift-off rather than axial motion. The signal from this accelerometer is noisier than the NEP $\mu \mathrm{g}$ accelerometers. This is in part due to a higher filter cutoff frequency $\left(f_{\mathrm{c}}=100 \mathrm{~Hz}\right)$ in its built-in signal conditioning module. This sensor had also experienced some shielding/ground-loop noise in prior runs which was never entirely eliminated, some noise was present even after modifications were made in the wiring which eliminated most, but not all, of the problem.

Page B-12, A9X accelerometer: Shock response at the A8T $\mu \mathrm{g}$ accelerometer mount. Response characteristics appear very similar to that of the NEP mount accelerometers (see pg. B-3 description) except that the amplitude is significantly higher at that location $(-225$ to $+203 \mathrm{~g}$ ), as expected.

Page B-13, A10X WES deck accelerometer: Response is similar to that at the NEP mounts and AFT support with variation in amplitudes.

Page B-14, A11X WES deck accelerometer: Response is similar to that of the A10X WES deck accelerometer.

Page B-15, A12 check channel: In this run, this spare DAS channel monitored the raw output signal from the A3R NEP $\mu$ g accelerometer, bypassing all but the dynamic ranging components in the built-in signal conditioning and filter module. This was designed to look at the raw output from the sensor before any conditioning to verify that signal from the sensor was not clipped. There is no evidence of this in the data, which proved that the electronic dynamic ranging scheme designed to reduce unwanted high-frequency vibration and shock sensitivity would be sufficient to protect the sensor and guarantee its performance during the shock event. This also demonstrated that additional mechanical isolation in the accelerometer mounts would not be required.

Page B-16, Scanning Laser Vibrometer: Processed velocity data (in inches/sec) from the laser vibrometer placed under the test unit to measure RV displacement and velocity after lift-off. 
Analysis View \& Edit MWS.vi

Last modified on 12/5/32 at 4:50 PM

\section{Printed on 10/7/98 at 2:04 PM}

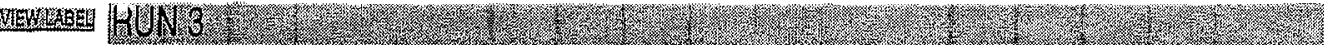

20

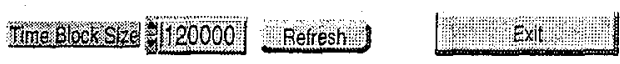

t) Linear $Y$ :

1.24.

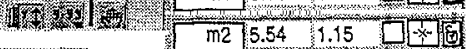

|Peak: $: 277344 E+2$

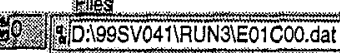

(3)

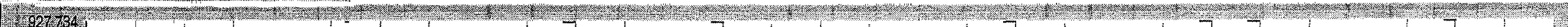

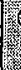

1.

1.2.

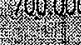

t. 62

tr.

1) 600.0

r.t.

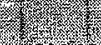

2. 2013

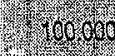

2. 006

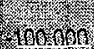

3rit.

200

60060

+2 406000

.

.

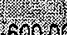

1.7. 7066

$x^{2}+2.72$

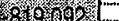

2.

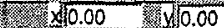

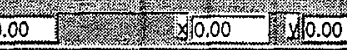

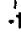

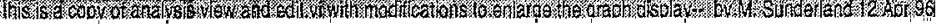


Analysis View \& Edit MWS.vi

Paye $1 \mid$

Last modified on 12/5/32 at 4:50 PM

Printed on 10/7/98 at 2:06 PM

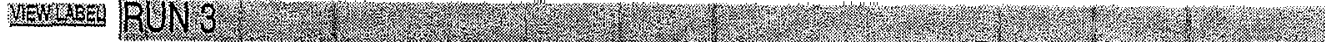

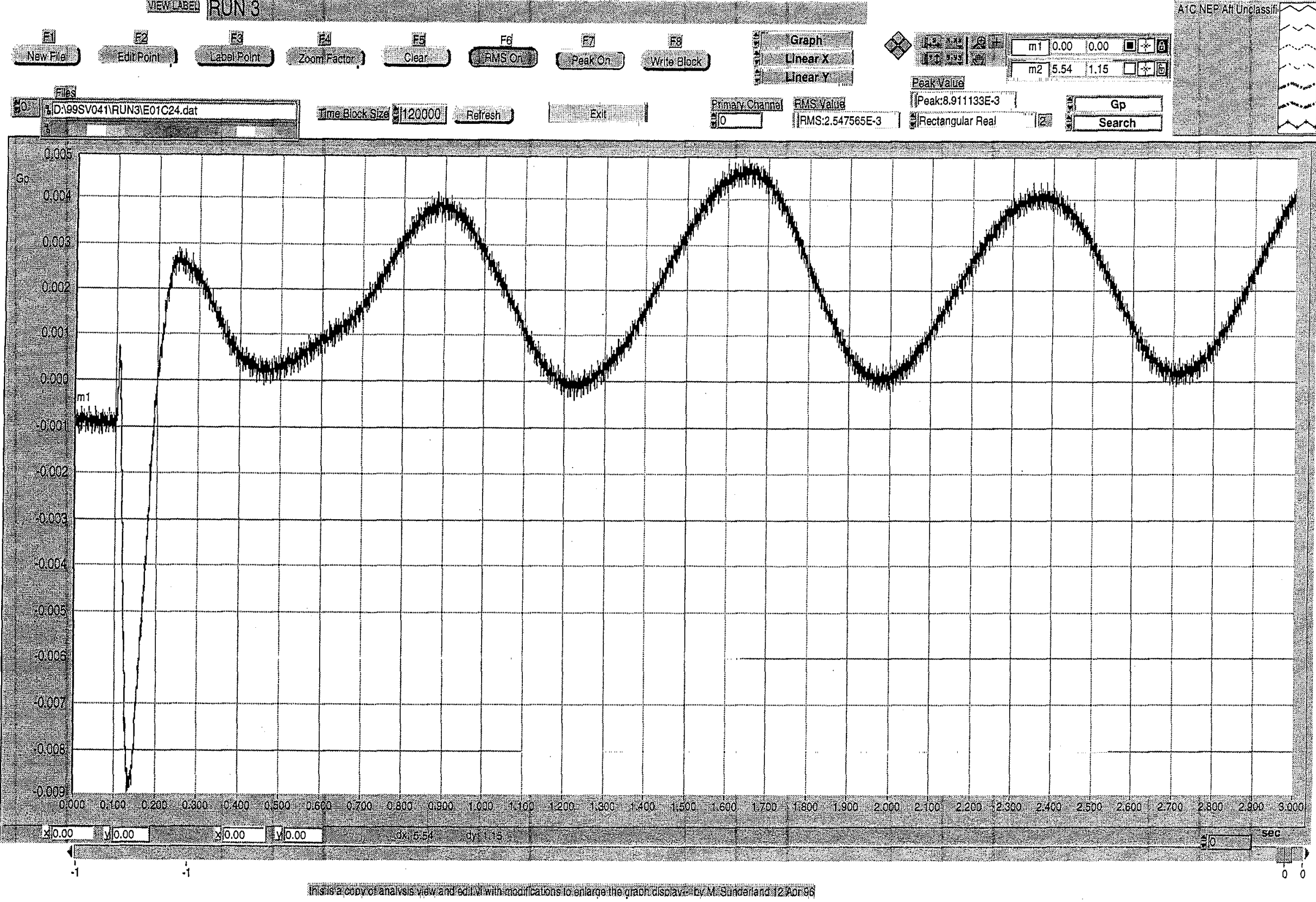


Analysis View \& Edit MWS.vi

Last modified on $12 / 5 / 32$ at $4: 50 \mathrm{PM}$

Printed on 10/7/98 at 2:04 PM

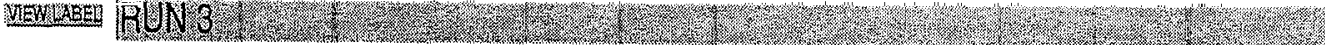

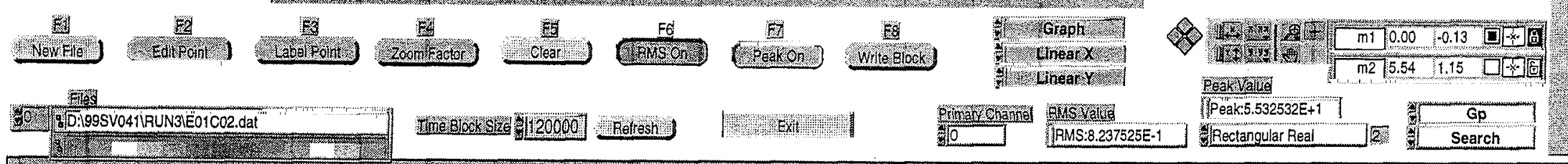


Analysis View \& Edit MWS.vi

Last modified on 12/5/32 at 4:50 PM

\section{Printed on 10/7/98 at 2:04 PM}

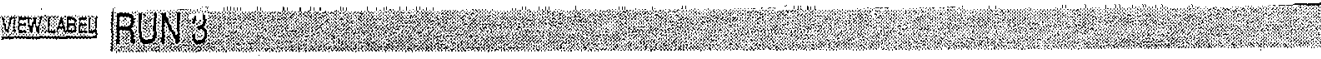

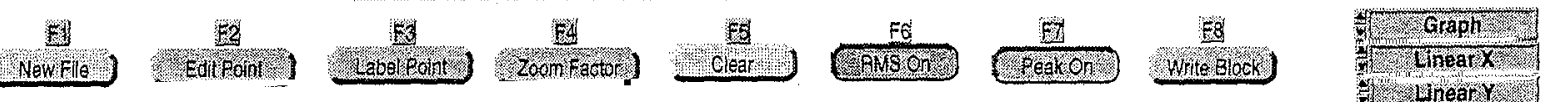

Hiles

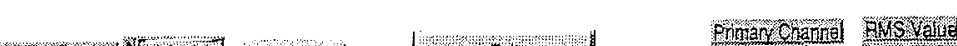

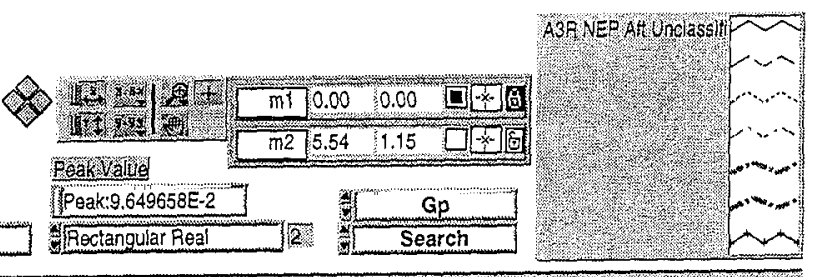

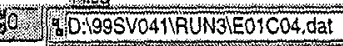

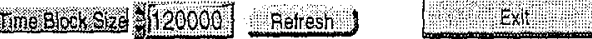

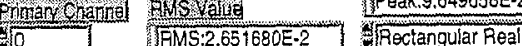

9p 0.090

0.080

0.27

0.070

0.06

0.96

0.055

0.650

0,45

7.0.9.80

6.0 .03

1. 6

0.020

006

$+0.605$

6000

20005

0.090

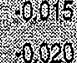

0.025

0

0035

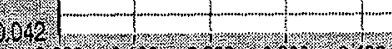

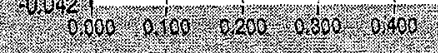

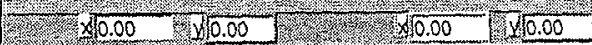

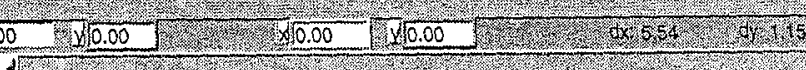

, 
Printed on 10/7/98 at 2:04 PM

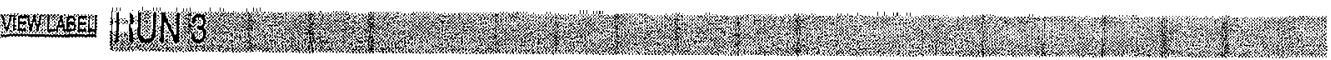

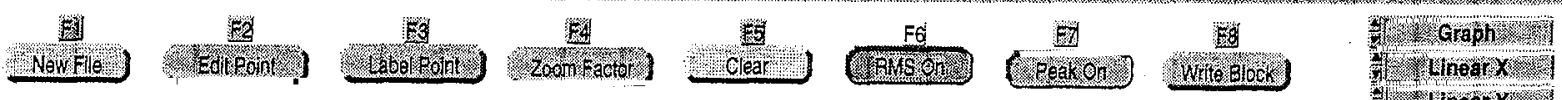

Fies

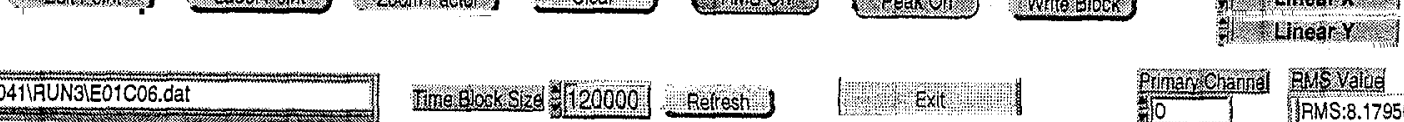

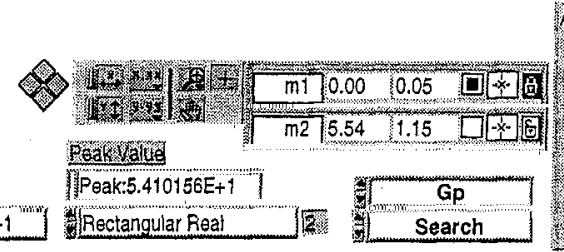

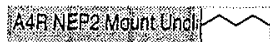

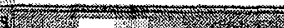

PRS:8.179501E-1

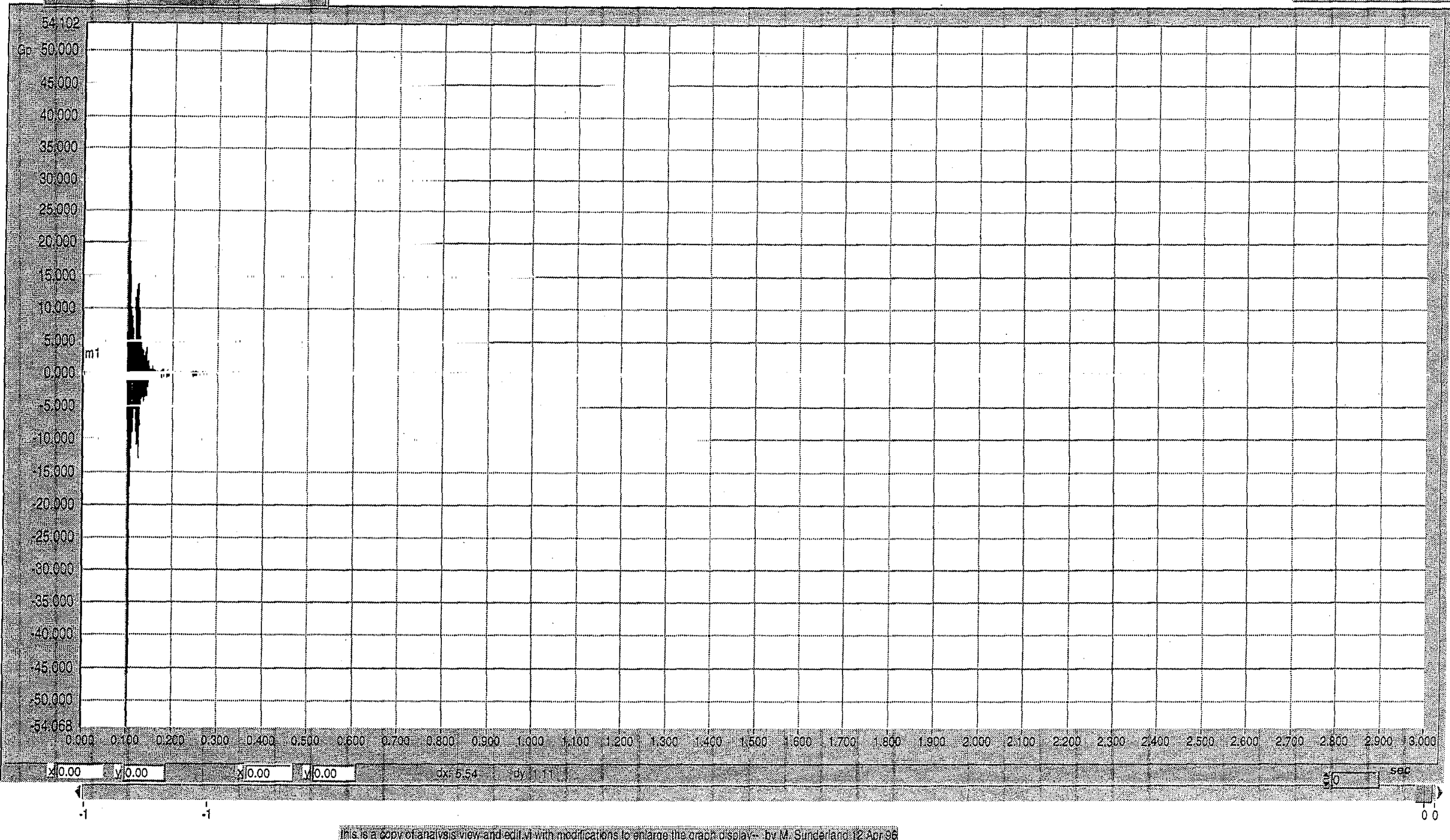


Analysis View \& Edit MWS.vi

Last modified on $12 / 5 / 32$ at $4: 50 \mathrm{PM}$

Paye $1 / \infty$

Printed on $10 / 7 / 98$ at 2:05 PM

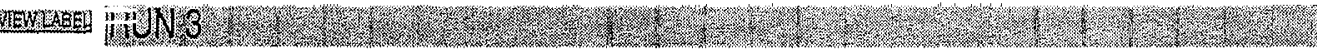

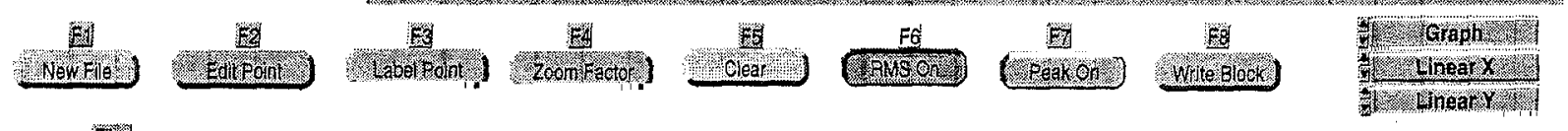

\section{0.

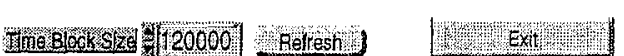

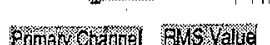

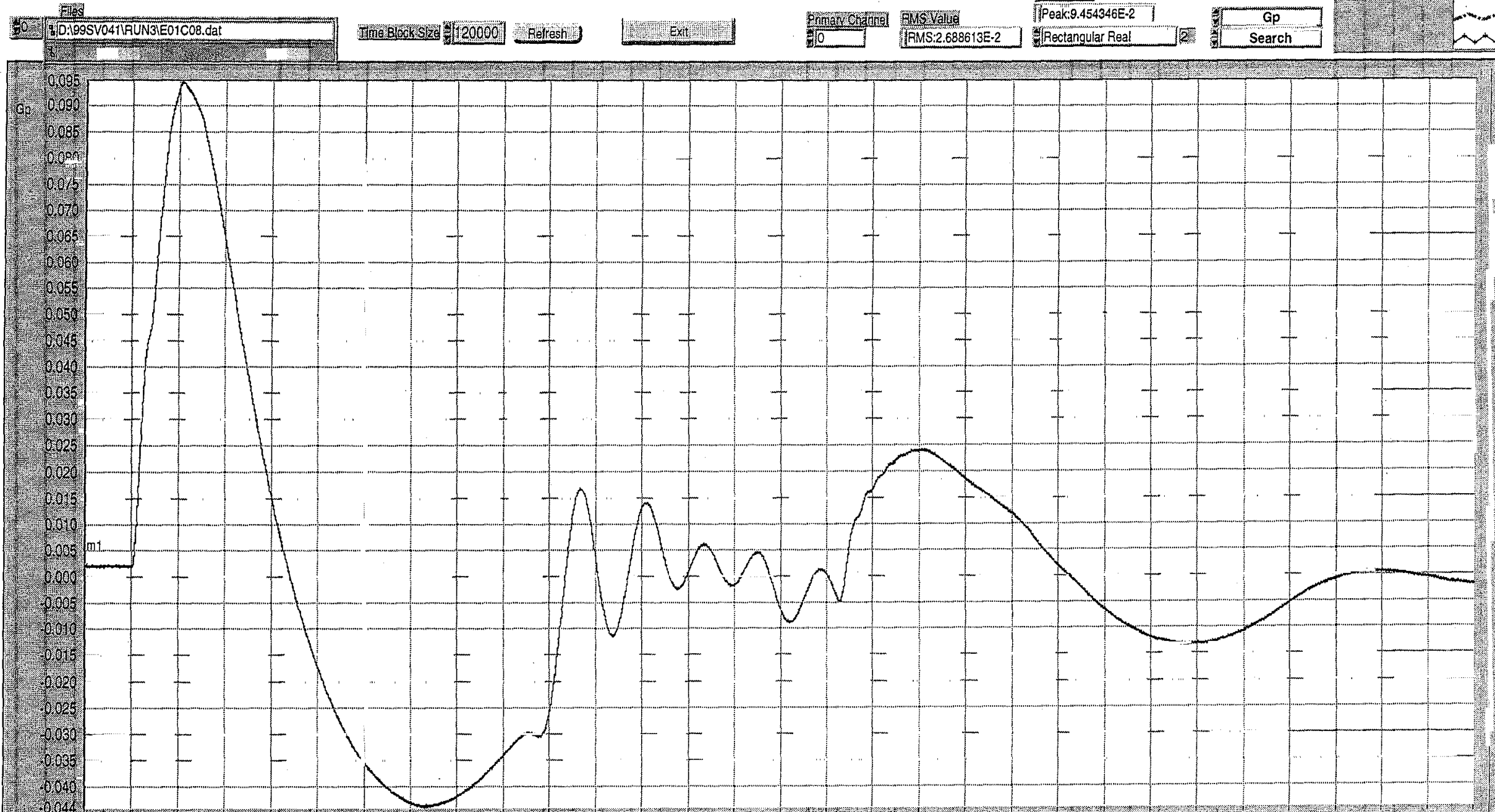

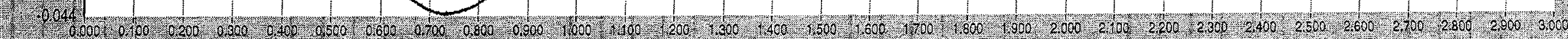

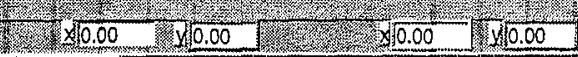


Analysis View \& Edit MWS.vi

Last modified on 12/5/32 at 4:50 PM

Paye $1 \mid a$

Printed on 10/7/98 at 2:05 PM

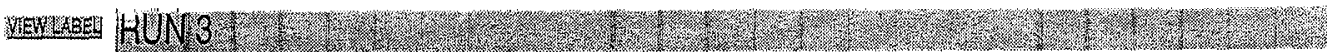

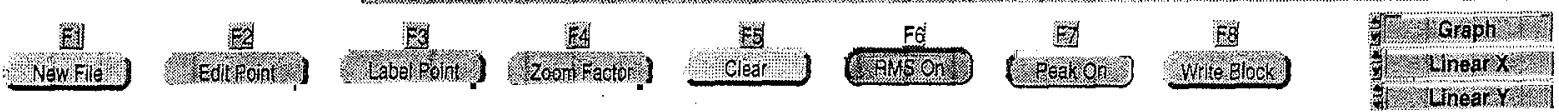

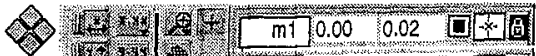

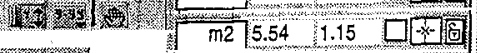

reavalue

Peak:7.932129E+1 I GP

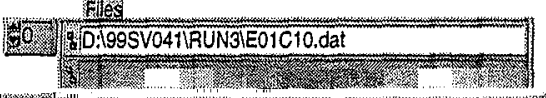

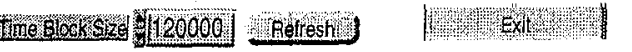

EMS:9.338131E-1 / Rectangular Re

楼 $\frac{\mathrm{GP}}{\mathrm{Search}}$

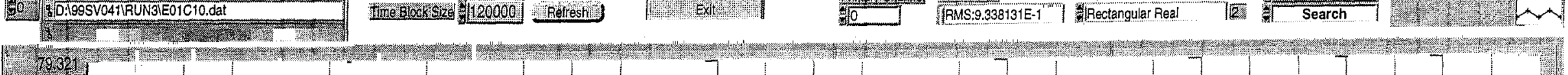

G) 65

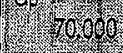

-6. $600 \mathrm{~g}$

- 26.5

2. 50.66

1.6.

+5 53

2. 60

20

-

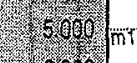

- 5

3060

- $15: 6060$

220049

20.6

-7. 35 .

406

- 150

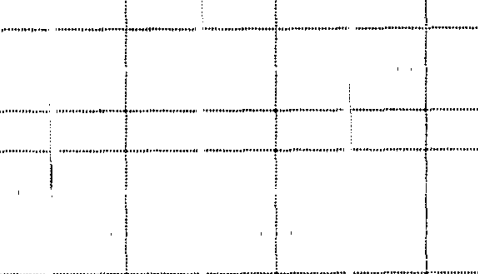

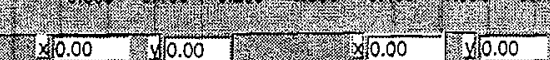

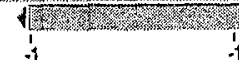

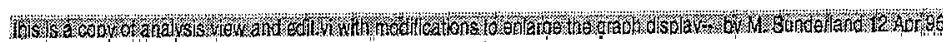


Analysis View \& Edit MWS.vi

Last modified on $12 / 5 / 32$ at 4:50 PM

Page 1 10

Printed on 10/7/98 at 2:05 PM

J4

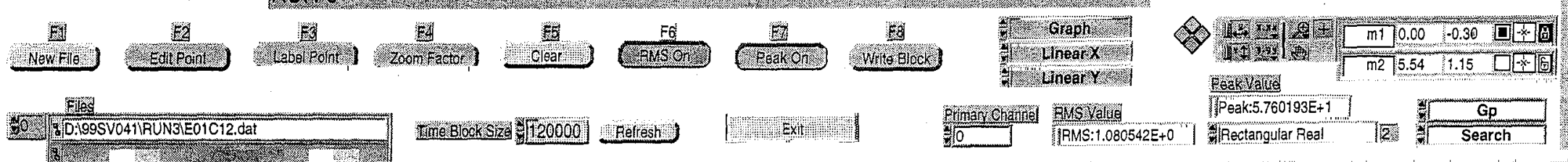

A7XAFisupport Uno

.

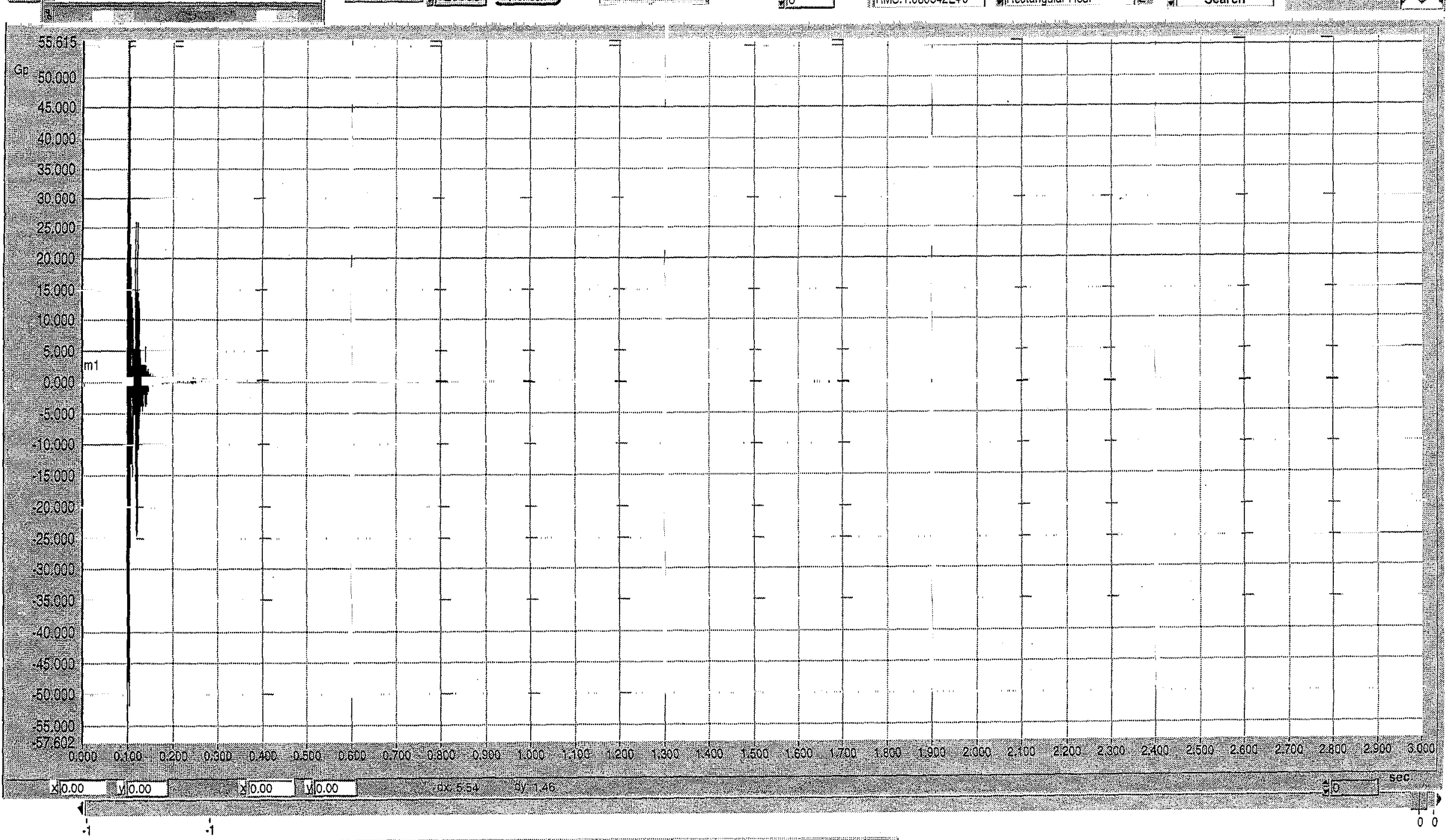

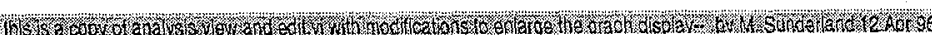


Printed on 10/7/98 at 2:05 PM

NAw

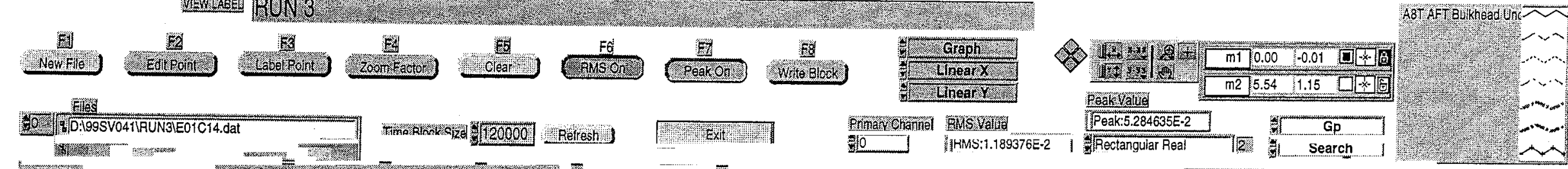

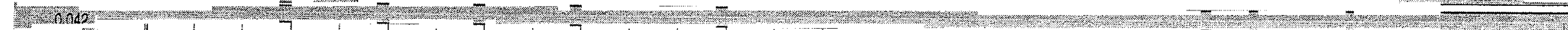

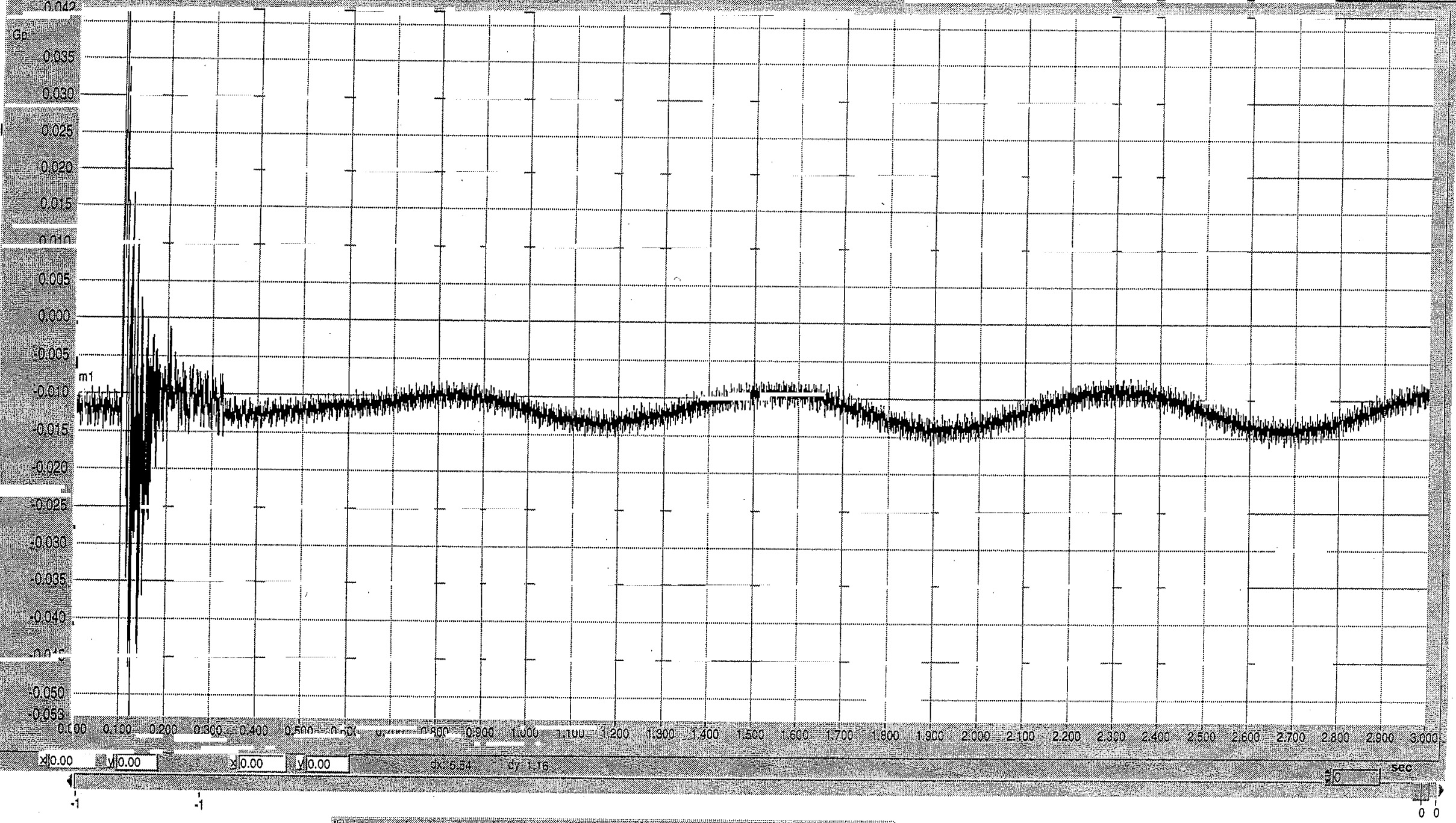

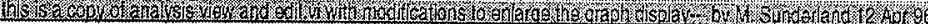


Analysis View \& Edit MWS.vi

Last modified on $12 / 5 / 32$ at $4: 50 \mathrm{PM}$

Page 1

Printed on 10/7/98 at 2:05 PM

MEX

Newerila

18

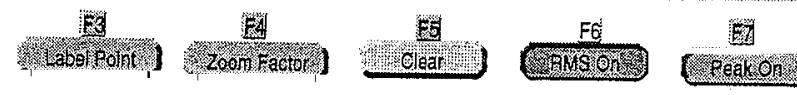

Creakon

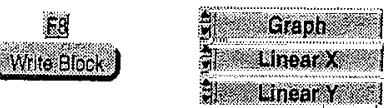

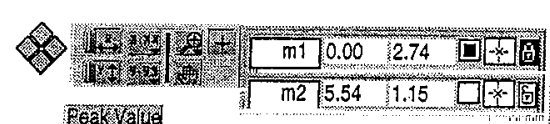

isilised

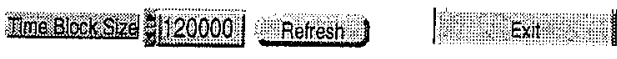

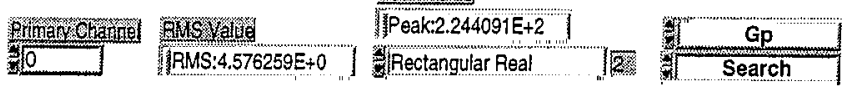

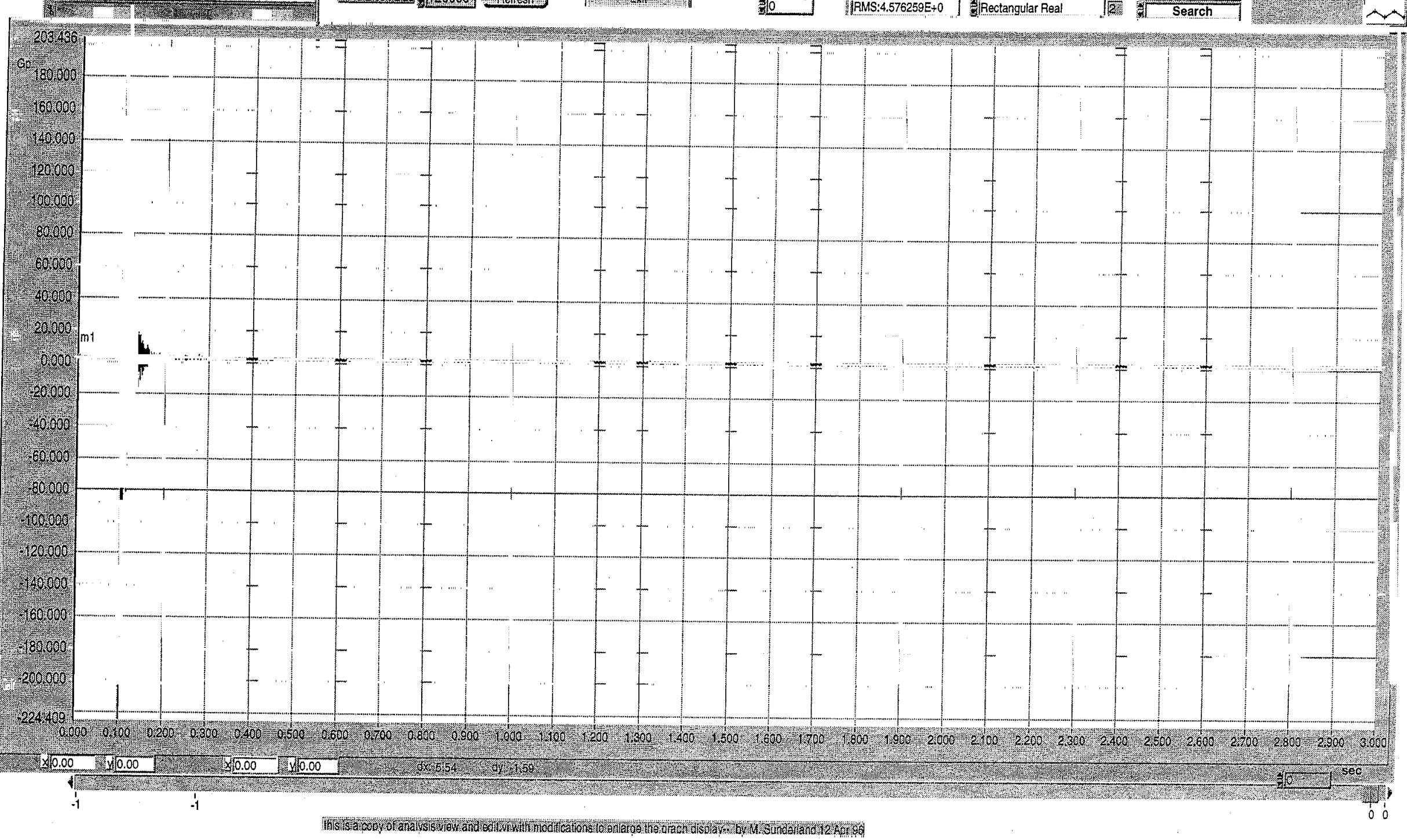


Analysis View \& Edit MWS.vi

Last modified on $12 / 5 / 32$ at $4: 50 \mathrm{PM}$

Paye 1 |

Printed on 10/7/98 at 2:06 PM

HEW

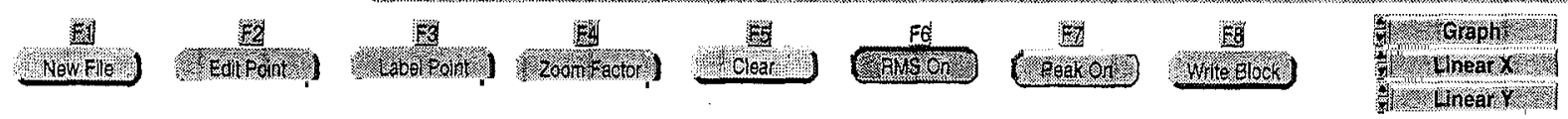

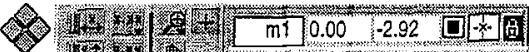

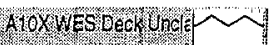

进这

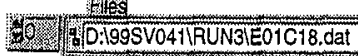

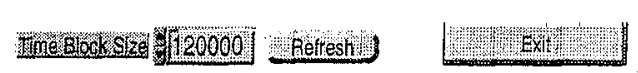

A

-

44.

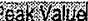

] $\frac{G p}{\text { Search }}$

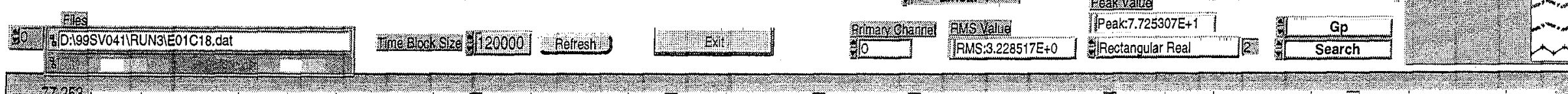

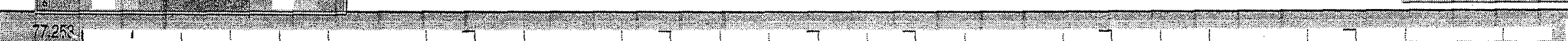

G. 360

2. 6 - 6

2. 606

2.

- 146

1.2.

2. 2016

25600

3.7. 5 .

2.

12. 5

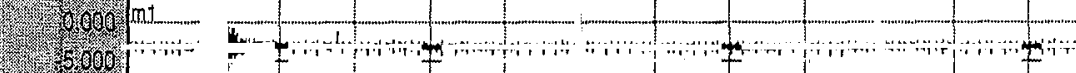

- 2.000

2.

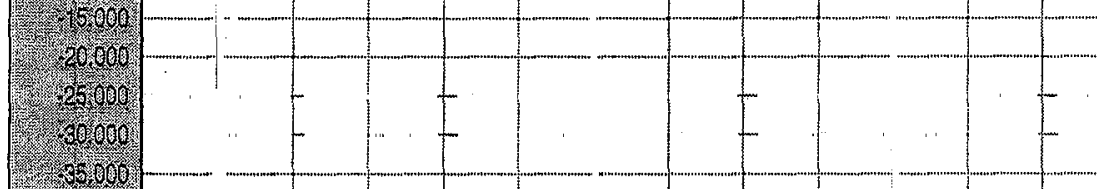

1.2.

T. 6.

1. 6 . 6.6

7. 5 . 60

- 600

(6)

2. 6.7 .6

3.4 .1000 .

$: 1$

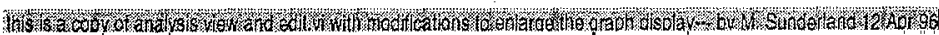


Analysis View \& Edit MWS.vi

Last modified on 12/5/32 at 4:50 PM

Printed on 10/7/98 at 2:06 PM

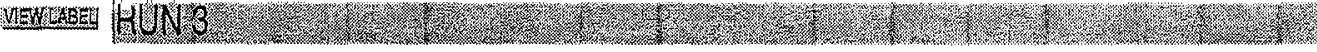

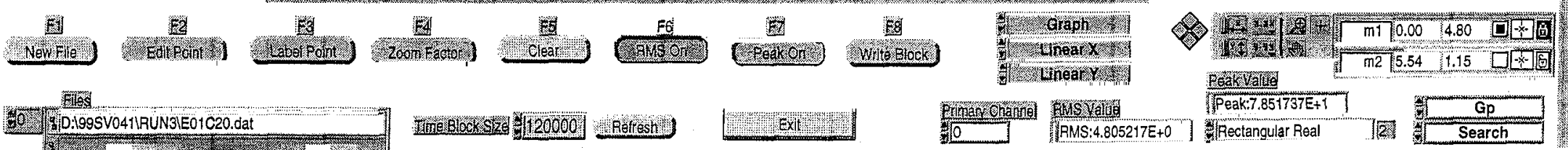

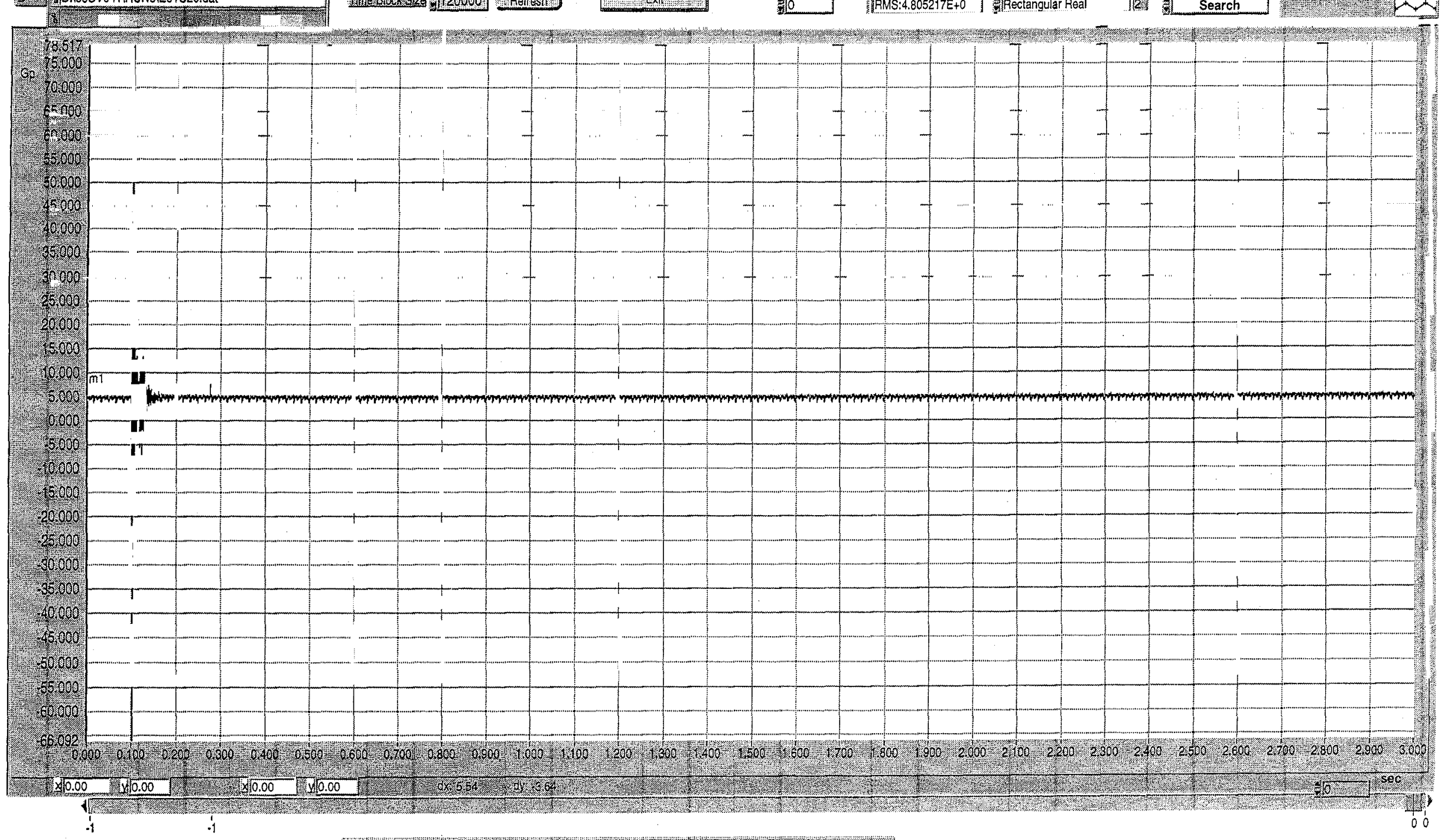

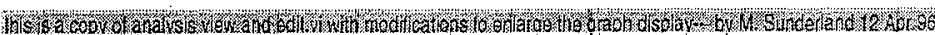


Analysis View \& Edit MWS.vi

Last modified on $12 / 5 / 32$ at 4:50 PM

Printed on 10/7/98 at 2:06 PM

H H

\section{国

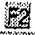 \\ Neivite

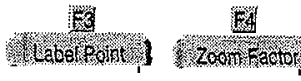 \\ 数

Fo \\ Fler: Graph: \\ 5) Linear $x$}

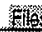

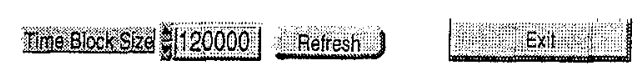

8.

101)

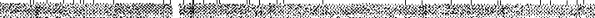

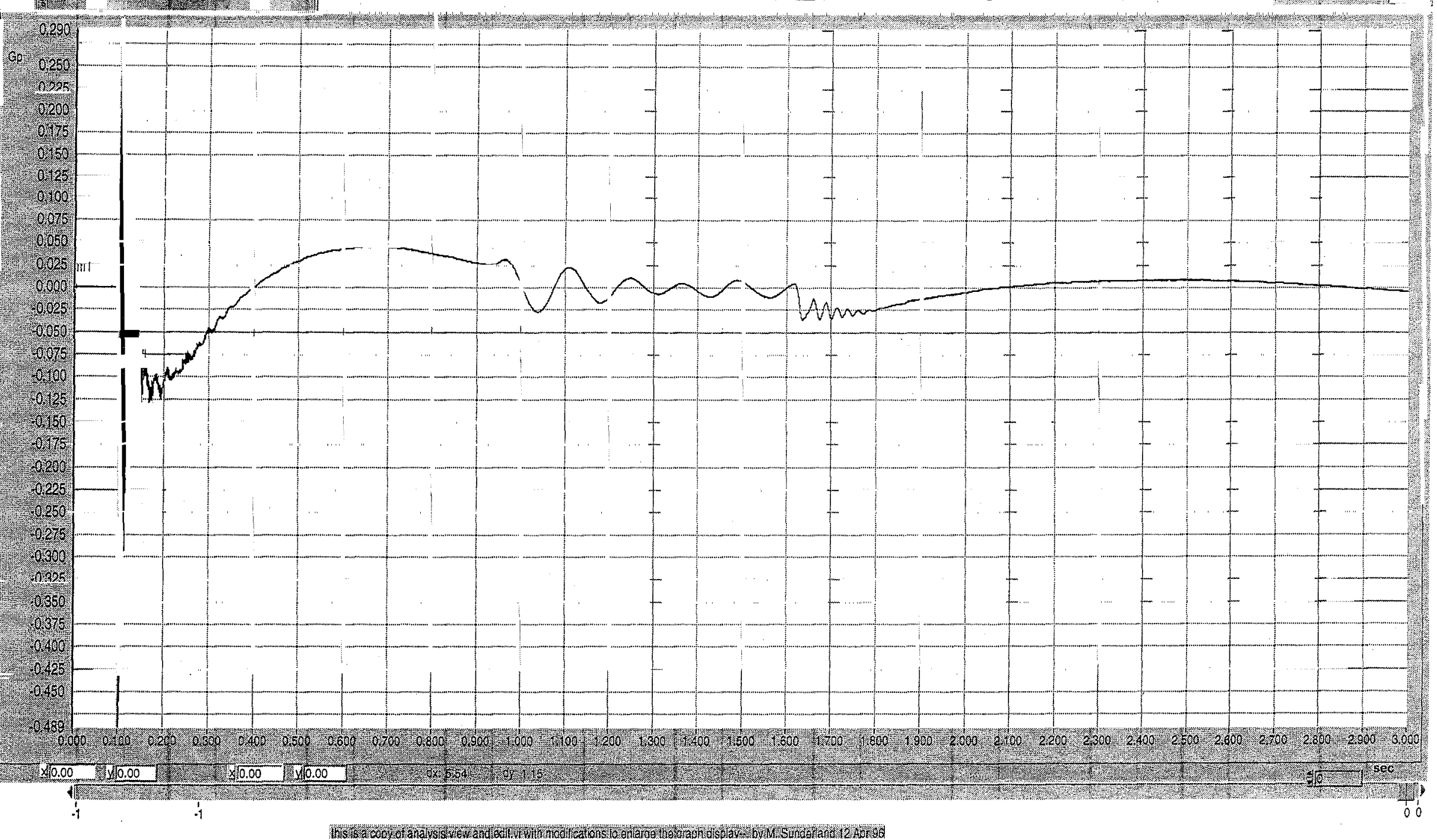

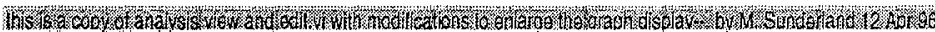


Analysis View \& Edit MWS.vi

Last modified on $12 / 5 / 32$ at 4:50 PM

Printed on 10/7/98 at 2:07 PM

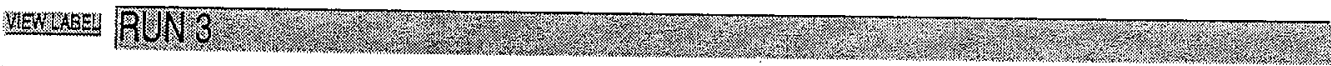

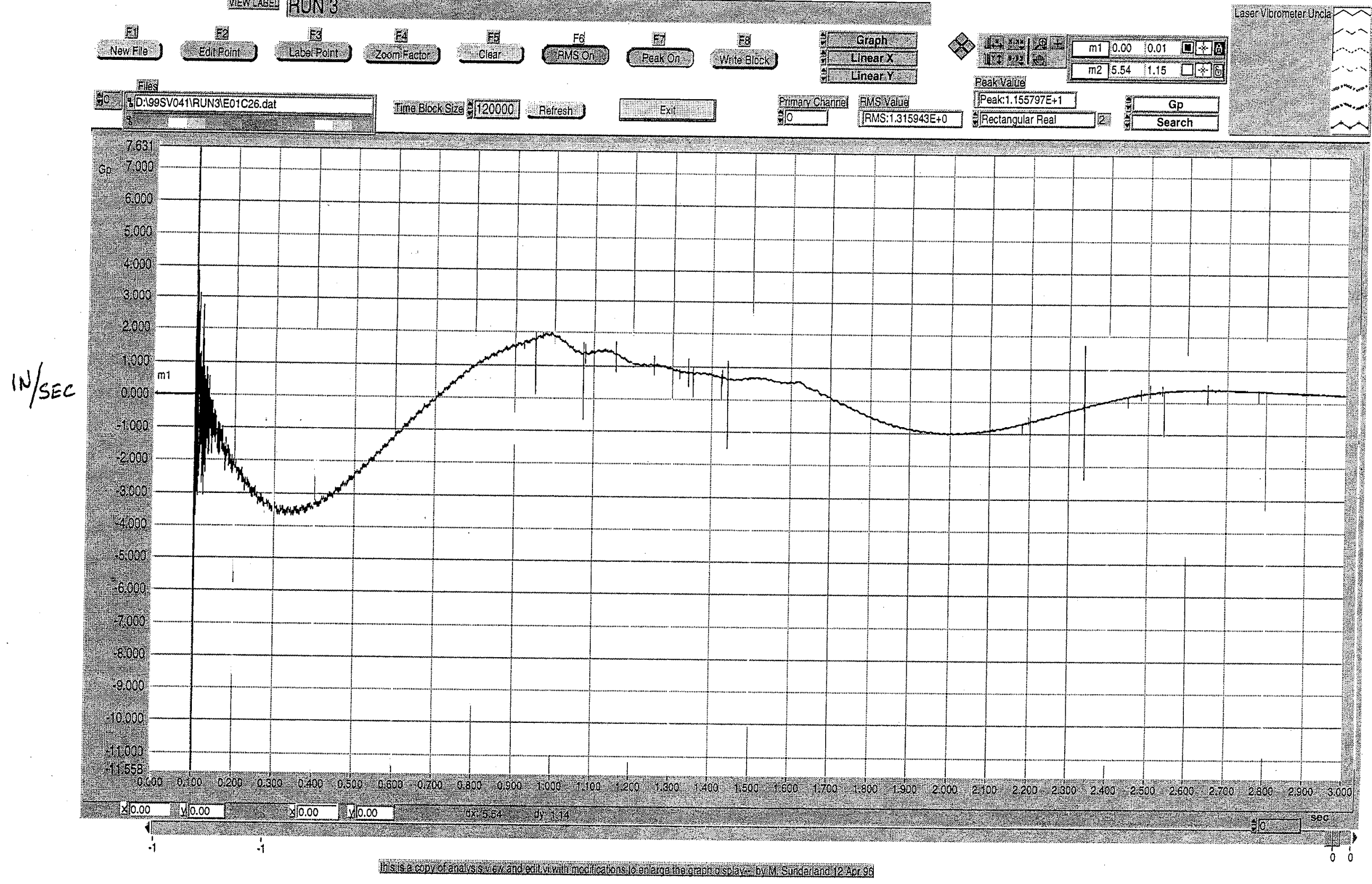

